\title{
Communication Modes Used for Information Sharing in Construction Projects of Pakistan
}

\author{
Noman Ahmed ${ }^{1}$, Aftab Hameed Memon ${ }^{2}$, Nafees Ahmed Memon ${ }^{3}$ \\ ${ }^{1}$ Research Scholar, Department of Civil Engineering, Mehran University of Engineering and Technology, \\ Jamshoro, Pakistan, nauman.ahmed1994@outlook.com \\ ${ }^{2}$ Associate Professor, Department of Civil Engineering, Quaid-e-Awam University of Engineering, Sciences and \\ Technology Nawabshah, Pakistan, aftabm78@ hotmail.com \\ ${ }^{3}$ Professor, Department of Civil Engineering, Mehran University of Engineering and Technology, Jamshoro, \\ Pakistan, nafees.memon@gmail.com
}

Received Date : September 02, 2021 Accepted Date : September 24, 2021 Published Date : October 07, 2021

\begin{abstract}
The construction industry is characterized as complex, fragmented, dynamic, and involves many parties. Therefore effective communication for information sharing is essential to overcome these challenges. A comprehensive review of previously published literature and questionnaire survey was done to collect this study's data. 161 responses collected from contractors, consultants, and clients were analyzed statistically. The results of the analysis reveal that the practitioners prefer to use Email, Drawings (CAD), Phone Calls, WhatsApp, and Site Meetings for communication. However, they mention that in comparison, Letters (Written Documents and Reports), Stakeholder meetings, Drawing (CAD), Site Meetings, and Phone Calls are more effective communication tools. Based on the discussion, it is summarized that important modes of communication are Drawing (CAD), Phone Calls, Site Meetings, Emails, and WhatsApp, which help in proper understanding and fast mode of communicating the messages. The respondents suggested that the government introduce and enforce the law to adopt modern communication modes for improved communication systems. Also, the practitioner should be motivated to work with virtual environments such as BIM for achieving successful projects.
\end{abstract}

Key words: communication, modes of communication, construction, Pakistan

\section{INTRODUCTION}

Success is the primary goal of all stakeholders involved in a construction project. Communication is one of the most critical factors contributing to success because of the numerous parties involved to work together and address the issues occurring on project sites [1]. Communication refers to exchanging information and other resources, such as ideas, knowledge, and skills among team members and organizations. Communication types are written (such as letters, emails, memos, reports, and formal documents), verbal (as chat, presentation, and voicemails), and non-verbal (as signals to communicate and study body language). Communication plays an essential role in building a successful project; some researchers believe that timely transfer of relevant information is necessary for project performance, so a proper mode of communication is necessary to deliver the data [2].

Communication in construction projects is either formal (using written means, e.g., letters, Emails, blueprints, and specifications) or informal (including verbal face-to-face or electronic means). Using multiple media, including face-to-face and electronic communications, can improve overall communication [3]. Communication is an essential element for every organization to succeed. Organizations cannot exist without communication, and management will not be able to receive information inputs. Supervisors will not be able to give instructions, coordination of work is impossible, and the organization will collapse for lack of it. Efficiency in a building depends upon the relationship quality between the client, professionals, contractors, and sub-contractors. Participants need to collaborate, share, collate and integrate significant amounts of information to realize project objectives [4]. During a construction project, irrespective of the size of the project, communication between the user (client), contractor, and other parties involved plays a vital role in the project. The project participants must provide timely and accurate information to all project stakeholders so that members of the project prepare information in various ways to meet the need of stakeholders to incorporate feedback from these stakeholders. Therefore, it is essential to develop a procedure to share information for timely and accurate information sharing efficiently. Project participants spend so much time in communications, and when projects get larger and more complex, it becomes more critical for them to provide adequate planning for communication. Even though several project communication plans exist in the construction 
industry, it is not easy to find proper communication modes for projects in the construction industry [5]. This paper aims to study the importance level of different modes of communication used in the construction industry to share information. Additionally, this research will also highlight the suggestions given by the professionals to improve information sharing.

\section{LITERATURE REVIEW}

\subsection{Construction Industry and Communication}

According to the Oxford dictionary, communication is defined as "The imparting or exchanging of information through speaking, writing, or using some other medium." Similarly, Longman dictionary defined communication as "the process by which people exchange information or express their thoughts and feelings." Communication can have various meanings, contexts, and forms that depend on the discipline referred accordingly. The critical aspect of both mentioned definitions introduced communication as sending or receiving information by different means. Communication conveys information by exchanging thoughts, messages, speech, visuals, signals, writing, and behavior. Effective communication generates the desired effect and increases the effectiveness of any message [6].The global construction industry is changing in response to new or improved management systems, new technologies and the need to expand and diversify. The construction industry has long been categorized as an information-intensive industry. As a result, improved information sharing and increased use of innovative information and communication technology tools are recognized as potential solutions to ensure significant improvements in communication efficiency, productivity, and overall industrial quality [7]. The relationship between the elements that make up the process associated with the construction industry depends on the client requirements and the selected procurement method for the delivery of the projects and selection of the appropriate techniques. Procurement of large-scale construction projects utilizing resources from different stakeholders requires a high degree of coordination and effective communication [8]. Developing effective strategies for construction projects requires knowledge and expertise in effective communication to work. Project managers spend about ninety percent of their time communicating; therefore, communication would be the most critical skill for project managers [9]. Construction projects operate in a dynamic, continuously changing environment where interactions and relationships are more complicated than in a stable, functional organization. The fundamental problem is the lack of communication channels which makes free information exchange difficult. Hence, different types of organizational structures or project-oriented information systems are needed. As projects get larger and more complex, communication and coordination become more and more complicated and become more vital to the success of a project [10]-[11].

\subsection{Communication in Construction}

Communication means mutual exchange of project information and processes with the assurance of creating an understandable platform between receiver and sender. In construction, communication covers all tasks related to producing, compiling, sending, storing, distributing, and managing project records. Communication is a process that runs throughout the project lifecycle and involves various stakeholders, so extensive information exchange across the members of a project is required. Effective communication entails that the process is well-coordinated through accurate information during all project phases. It provides the base for creating the necessary alliances for a successful project. Good communication can substantially improve teamwork and a higher level of collaboration in a construction project [1]. The project's final results are affected by the communication and coordination of the project processes that seek to meet the expectation of the client. Therefore, it is a significant need to manage and coordinate the exchange of this information among participants. Thus, improvement in communication can use a proper mode of communication to lead to the success of a project.

\subsection{The Importance of Communication}

Nowadays, the importance of effective communication cannot be over-emphasized. Almost every manuscript on managing people will cover essential principles of how to communicate effectively with the personnel. People find it hard to operate in the industry at an individual and team level if they do not develop a proper communication plan to underpin their work activities [12]. Likewise, the management of construction projects also calls for establishing dynamic and effective communication modes that allow their numerous mechanisms to adjoin appropriately. In construction projects, because of its decentralized nature caused by the geographical distribution of projects participants, the different responsibilities of various parties, and different times to join the construction teams, it has highlighted the importance of modern communication modes [13]. Communication difficulties during the project process can directly lead to a sharp increase in unnecessary expenditure and affect the progress and quality of the project [10]. Therefore, the efficiency and effectiveness of the construction process strongly depend on the quality of communication among the client, contractor, and consultant.

Moreover, open communication at all levels could lead to innovations and better technical solutions. Communication improvements in the early phases of projects would positively influence the quality perceived by all stakeholders involved. Improved communication during the briefing might lead to better decision-making [14]. The lifecycle of construction projects may be very long, and there are different tasks at different stages. Ever-changing parties who adopt varying forms of communication must complete these tasks making it impossible to collect all the communication information about all the tasks. 
Each participant is not a person but an organization. Different organizations have different organizational structures. The various departments of these organizations communicate with the outside world through specific individuals, which gives more variables to construction project communication [15]. A construction project has always been a team effort. Numbers of individuals, parties as well as stakeholders work together to achieve the project goal. Therefore, effective communication helps to reduce uncertainties of individuals and minimize time-wasting on communication planning [16]. Communication does not only occur between individuals but can occur between groups or organizations. Construction is inherently a team activity involving the concurrent involvement of many specialists to achieve efficaciously project objectives [13].

\subsection{Modes of Communication}

This skill is intrapersonal and interpersonal processing, listening, observing, speaking, questioning, analyzing, and evaluating. Collaboration and cooperation occur through communication. Project meetings, hard-copy documentation, databases, email, telephone calls, video conferences, project websites, and other methods help share information according to project demands and as technology provides [13]. At every stage of the construction lifecycle, information (in the form of drawings, specifications, notes, letters, memos, models, catalogs, instruction manuals, and pictures) needs to be stored, retrieved, and communicated [17]. Different methods of internal communication exist: Oral communication takes place in the form of meetings, discussion groups, talks, and conversations, both face to face and over the telephone. Written communication takes place using letters and emails. Electronic communication makes it possible to send messages all over the world at a very high speed. Messages are sent and received using computer terminals, electronic mail. Visual communication takes place using presentations and videos [18]. Project information is communicated through many modes: the project office, face-to-face, video conferencing, documents for project planning, meetings, portals for the project, email, telephone, and smartphone. These can be viewed as channels to communicate information. Communication methods utilized during construction should be appropriate to those times and conditions [15]. The adoption of information communication technology in construction and to enhance information and communication technology (ICT) application for better productivity. More advanced ICT appliances like site surveillance technologies (CCTV) and video conferencing [19]. Literature review helped to identify various modes of communication used in the construction industry, as summarized in Table 1.

Table 1: Mapping of Modes of Communication

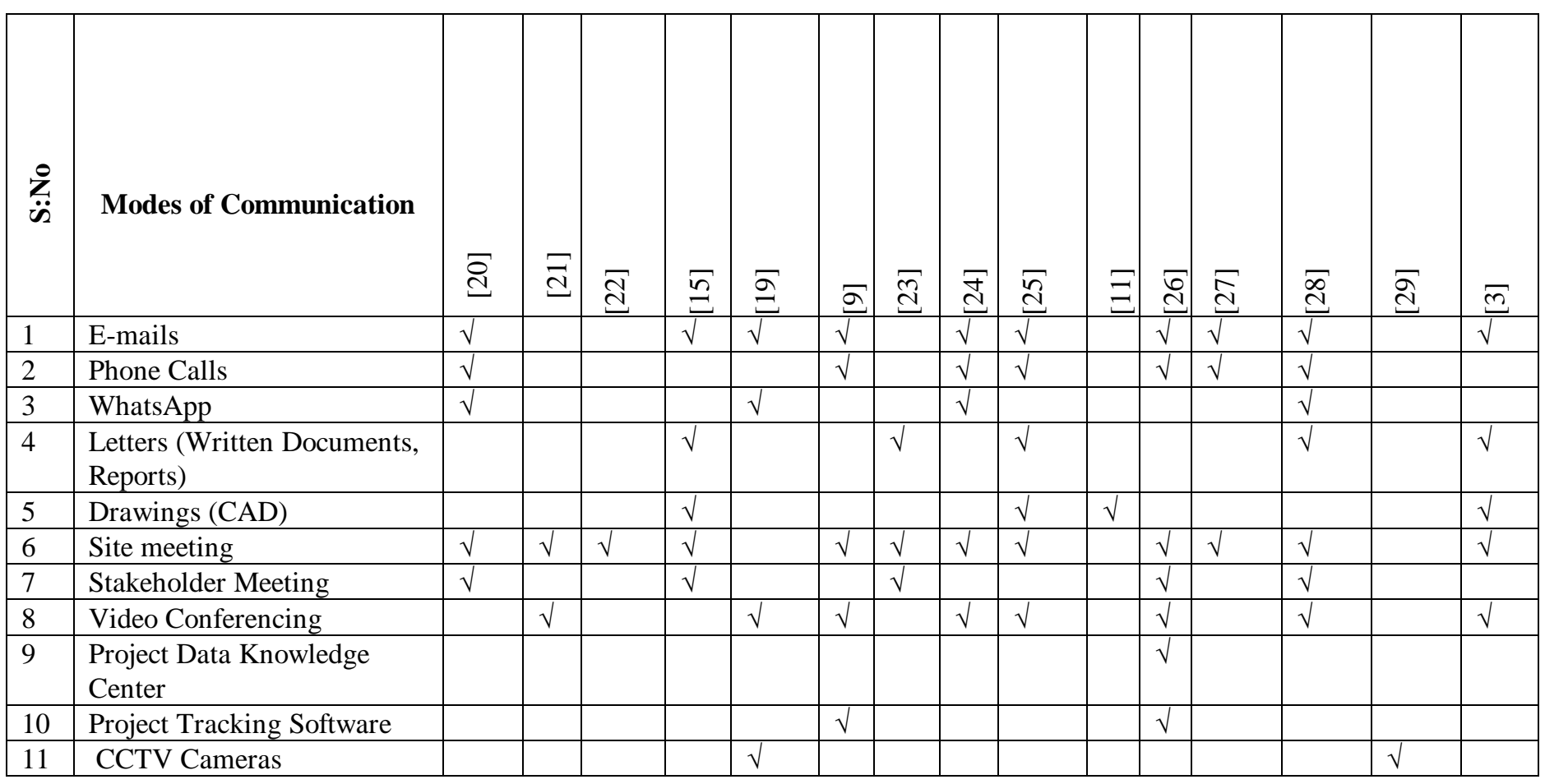

\section{METHODOLOGY}

A quantitative method of research helped to conduct this study. Different modes of communication identified from the literature, as in table 1, were used for the investigation to determine standard modes of communication used on construction projects. Data collection involved a semi-structured questionnaire survey. The practitioners working in construction organizations indicated the level of 
adoption and effectiveness for each mode of communication with a 5-point Likert scale.

A total of 168 responses were received, from which 161 responses were retained for analysis with the help of SPSS software package. The analysis involved the computation of three types of indices:

Occurrence Index: This index expresses the occurrence frequency of mode of communication. It is computed as per the following formula

$$
\text { O.I }=\frac{\sum_{0}^{5}\left(a_{i} m_{1}\right)}{5 N}
$$

Where: $\mathrm{a}=$ constant expressing the weight assigned to each response (ranges from 1 for Never occurring to 5 for Always occurring), $\mathrm{n}=$ frequency of each answer, $\mathrm{N}=$ total number of responses.

Effectiveness Index: This index expresses the effectiveness of mode of communication. It is computed as per the following formula:

E.I $=\frac{\sum_{0}^{5}\left(\mathrm{a}_{1} \mathrm{n}_{\mathrm{i}}\right)}{5 \mathrm{~N}}$

Where: $\mathrm{a}=$ constant expressing the weight assigned to each response (ranges from 1 for Not Effective to 5 for Extremely effective), $\mathrm{n}=$ frequency of each answer, $\mathrm{N}$ $=$ total number of responses.

Importance index: This index expresses the importance level of the mode of communication. It is determined with occurrence and effectiveness level using the following formula:

IMP.I. = O.I. * E.I.

\section{RESULTS AND DISCUSSION}

This section discusses the results obtained from the analysis of gathered data through a questionnaire survey. Before discussing the results, the profile of the respondents is explored to ensure the capability and technical knowledge level of the respondents participating in the data collection, as discussed in the following subsections.

\subsection{Demography of respondents}

The demography of the respondents describes the factual information of the respondents. The data of demographic characteristics of the respondents are summarized and presented in table 2 .

Table 2: Demographic Information of the Respondents

\begin{tabular}{|l|l|l|l|}
\hline Measure & Item & Count & $\%$ \\
\hline Qualification & Bachelors & 103 & 63.97 \\
of the & Masters & 45 & 27.95 \\
respondents & Post Graduate Diploma & 3 & 1.86 \\
& Diploma & 9 & 5.56 \\
\hline
\end{tabular}

\begin{tabular}{|l|l|l|l|}
\hline & B-Tech & 1 & 0.62 \\
\hline Position of & Director & 3 & 1.86 \\
the & General Manager & 2 & 1.24 \\
respondents & Construction Manager & 4 & 2.48 \\
& Assistant project Manager & 28 & 17.39 \\
& Project Manager & 3 & 1.86 \\
& Planning Engineer & 18 & 11.18 \\
& Site Engineer & 58 & 36.02 \\
& Assistant Engineer & 28 & 17.39 \\
& Sub Engineer & 12 & 7.45 \\
& Executive Engineer & 2 & 1.24 \\
& Quality Control Supervisor & 3 & 1.86 \\
\hline Type of & Infrastructure & 45 & 27.95 \\
projects & Residential & 12 & 7.45 \\
handled by & Non-Residential & 27 & 16.77 \\
respondents & Roads and Bridge works & 33 & 20.49 \\
& Oil and Gas Works & 14 & 8.69 \\
& Energy Related Works & 9 & 5.59 \\
& Irrigation & 4 & 2.48 \\
& Social Amenities & 17 & 10.55 \\
\hline Experience & 0 to 4 & 65 & 40.37 \\
& $>4$ to 8 & 32 & 19.87 \\
& $>8$ to 12 & 28 & 17.39 \\
& $>12$ to 16 & 21 & 13.04 \\
& $>16$ to 20 & 9 & 5.59 \\
& $>20$ & 6 & 3.72 \\
\hline Gender & Male & 152 & 94.4 \\
& Female & 9 & 5.59 \\
\hline
\end{tabular}

Table 2 shows that majority of the respondent (i.e., 63\%) have completed their B.E in civil engineering, while $28 \%$ are master's degree holders. These respondents are holding engineering and management positions in their organizations. In addition, they have experience holding several types of projects such as residential, non-residential, and infrastructural works for several years. This shows that the respondents have technical knowledge and are qualified to give the required and reliable information.

\subsection{Reliability Analysis}

A reliability test checks the stability and consistency of data. It uses Cronbach $\alpha$ method, and a generally accepted rule is that value of 0.6 to 0.7 indicates an acceptable level of reliability, and 0.8 or greater is an excellent level. However, values higher than 0.95 are not necessarily good since they might indicate redundancy [30]. From the analysis it is identified that Cronbach $\alpha$ value for the occurrence of modes of communication and effectiveness of modes of communication are 0.718 and 0.849 , respectively.

\subsection{Modes of Communication in Construction Projects} This study used descriptive analysis of the data to assess the importance level of the various modes of communication. Based on RII value, the results showing the level of occurrence and ranking are in table 3. 
Noman Ahmed et al., International Journal of Emerging Trends in Engineering Research, 9(10), October 2021, 1305 - 1311

Table 3: Occurrence of Modes of Communication

\begin{tabular}{|c|c|c|c|c|c|c|c|c|}
\hline $\begin{array}{c}\text { S } \\
\text { No }\end{array}$ & Modes Of Communication & NO & SO & MO & UO & AO & RII Occurrence & $\begin{array}{c}\text { Ran } \\
\mathrm{k}\end{array}$ \\
\hline 1 & Email & 7 & 11 & 19 & 42 & 59 & 0.831 & 1 \\
\hline 2 & Drawing (CAD) & 5 & 4 & 18 & 52 & 59 & 0.826 & 2 \\
\hline 3 & Phone Call & 5 & 4 & 19 & 63 & 47 & 0.807 & 3 \\
\hline 4 & WhatsApp & 4 & 8 & 39 & 48 & 39 & 0.759 & 4 \\
\hline 5 & Site Meeting & 19 & 4 & 47 & 57 & 26 & 0.740 & 5 \\
\hline 6 & Project Tracking Software & 5 & 43 & 47 & 16 & 27 & 0.624 & 7 \\
\hline 7 & Letters (Written Documents and Reports) & 2 & 37 & 71 & 12 & 16 & 0.604 & 8 \\
\hline 8 & Stakeholder Meeting & 15 & 48 & 45 & 24 & 6 & 0.539 & 9 \\
\hline 9 & Project Data Knowledge Centre & 18 & 56 & 52 & 7 & 5 & 0.491 & 10 \\
\hline 10 & Video Conferencing & 62 & 45 & 20 & 9 & 2 & 0.373 & 11 \\
\hline 11 & CCTV Cameras & & & & & & & \\
\hline
\end{tabular}

Table 3 depicts that Email is the most common mode of communication, having O.I of 0.831 followed by Drawings (CAD) and Phone Calls having O.I of 0.826 and 0.807, respectively. On the other hand, video Conferencing and CCTV Cameras are the least occurring mode of communication, having O.I of 0.491 and 0.373 , respectively. Similarly, we ranked the modes of communication with RII value to determine the modes' effectiveness level, as presented in table 4 .

Table 4: Effectiveness of Modes of Communication

\begin{tabular}{|c|c|c|c|c|c|c|c|c|}
\hline $\begin{array}{c}\text { S } \\
\text { No }\end{array}$ & Modes Of Communication & NE & LE & ME & VE & EE & $\begin{array}{c}\text { RII } \\
\text { Effectiveness }\end{array}$ & $\begin{array}{c}\text { Ran } \\
\mathrm{k}\end{array}$ \\
\hline 1 & Email & 7 & 16 & 41 & 42 & 32 & 0.7101 & 7 \\
\hline 2 & Drawing (CAD) & 2 & 5 & 17 & 73 & 41 & 0.8116 & 3 \\
\hline 3 & Phone Call & 2 & 4 & 52 & 37 & 43 & 0.7667 & 5 \\
\hline 4 & WhatsApp & 2 & 2 & 69 & 40 & 25 & 0.7217 & 6 \\
\hline 5 & Site Meeting & 10 & 13 & 40 & 61 & 14 & 0.6812 & 8 \\
\hline 6 & Project Tracking Software & 4 & 6 & 9 & 59 & 60 & 0.8391 & 1 \\
\hline 7 & Letters (Written Documents and Reports) & 2 & 7 & 15 & 57 & 57 & 0.8319 & 2 \\
\hline 8 & Stakeholder Meeting & 11 & 10 & 70 & 38 & 9 & 0.6348 & 9 \\
\hline 9 & Project Data Knowledge Centre & 13 & 22 & 73 & 23 & 7 & 0.5841 & 10 \\
\hline 10 & Video Conferencing & 20 & 50 & 49 & 12 & 7 & 0.5072 & 11 \\
\hline 11 & CCTV Cameras & & & & & & & \\
\hline
\end{tabular}

Table 4 shows that Written Documents (Letters and Reports) are the most effective mode of communication, having EI of o.8391 followed by Stakeholder Meeting and Drawing (CAD), having EI of 0.8319 and 0.8116 , respectively. On the other hand, video Conferencing and CCTV Cameras are the minor effective modes of communication, having EI of
0.5841 and 0.5072 , respectively. We used occurrence level and effectiveness level of the communication modes to determine the importance level of each mode of communication and ranked in table 5.

Table 5: Importance Index of Modes of Communication

\begin{tabular}{|c|c|c|c|}
\hline S No & Modes Of Communication & Importance Index & Overall Rank \\
\hline 1 & Email & 0.590 & 4 \\
\hline 2 & Drawing (CAD) & 0.670 & 1 \\
\hline 3 & Phone Call & 0.618 & 2 \\
\hline 4 & WhatsApp & 0.547 & 3 \\
\hline 5 & Site Meeting & 0.599 & 8 \\
\hline 6 & Project Tracking Software & 0.453 & 6 \\
\hline 7 & Letters (Written Documents and Reports) & 0.523 & 7 \\
\hline 8 & Stakeholder Meeting & 0.502 & 9 \\
\hline 9 & Project Data Knowledge Centre & 0.342 & 10 \\
\hline 10 & Video Conferencing & 0.286 & 11 \\
\hline 11 & CCTV Cameras & 0.189 & \\
\hline
\end{tabular}


Table 5 shows that Drawing (CAD) is the most critical mode of communication followed by phone calls. A site meeting is in third place as an important mode of communication. Video conferencing and CCTV cameras are the least essential modes of communication on construction projects in Pakistan.

\section{CONCLUSION AND SUGGESTIONS}

This study reported that Email, Drawings (CAD), Phone Calls, WhatsApp, and Site Meetings are the most commonly used modes of communication for information sharing used in construction projects of Pakistan. On the other hand, Letters (Written Documents and Reports), Stakeholder meetings, Drawing (CAD), Site Meetings, and Phone Calls are the most effective modes of communication. The top 5 modes based on the importance index are Drawing (CAD), Phone Calls, Site Meetings, Emails, and WhatsApp. At the same time, video Conferencing and CCTV were the least used and least effective modes. Analysis of data shows that traditional modes of communication are standard in the construction industry of Pakistan. However, it has not shifted to the modern modes of communication. Following are the suggestion given for adopting current communication modes for efficient and effective information sharing:

- The government should change laws to adopt modern communication modes for faster and efficient communication in the construction industry.

- Government should conduct awareness seminars for professionals and inform them about the potential benefits of adopting modern communication technology in the construction sector.

- Stakeholders should develop a project knowledge center.

- They employ personals and experts having knowledge and experience of modern technologies used in construction projects.

- A data-sharing center should be established to share plans and drawings that the senior will easily review using system checks before any approval.

- High Internet facilities should be installed for a better experience of video conferencing and CCTV cameras.

- Stakeholders should use a multirotor drone for site surveillance.

- Use Building Information Modeling (BIM) for better understanding and sharing of design and drawings.

- Adopt Integrated Virtual Reality-based communication systems mainly in mega projects.

\section{REFERENCES}

1. Safapour, E., Kermanshachi, S., et al. Identifying Effective Project-Based Communication Indicators within Primary and Secondary Stakeholders in Construction Projects, Journal of Legal Affairs and Dispute Resolution in Engineering and Construction, 11(4), pp. 1-10. doi: 10.1061/(ASCE)LA.1943-4170.0000332, 2019.

2. Nipa, T. J. and Kermanshachi, S. Development of Effective Communication Framework Using Confirmatory Factor Analysis Technique, ASCE International Conference on Computing in Civil Engineering, pp. 1-8, 2018.

3. Shohet, I.M. and Frydman, S. Communication patterns in construction at construction manager level, Journal of construction engineering and management, 129(5), pp.570-577, 2003.

4. Ishaq, I. M., Omar, R. and Musa, M. Challenges of Communication between the Client and Contractor during Construction Projects: The Nigerian Perspective, International Journal of Engineering and Modern Technology, 4(2), pp. 20-29, 2018.

5. Muszyńska, K. Communication management in project teams - practices and patterns, Proceedings of the MakeLearn and TIIM Joint International Conference 2015, pp. 1359-1366, 2015.

6. Rahman, Ismail Abdul, and Yaser Gamil. Assessment of cause and effect factors of poor communication in construction industry, IOP Conference Series: Materials Science and Engineering, vol. 601, no. 1, p. 012014. IOP Publishing, 2019.

7. Othman, A., Hisham Gabr, T. Aziz, and M. Hussien. Causes and impacts of poor communication in the construction industry, 2nd International Conference on Sustainable Construction and Project Management-Sustainable Infrastructure and Transportation for future Citie, 2018.

8. Lee, Namhun, and Yeojin Kim. A conceptual framework for effective communication in construction management: Information processing and visual communication. Construction Research Congress 2018, pp. 531-541. 2018.

9. Taleb, H., S. Ismail, M. H. Wahab, W. N. Mardiah, W. M. Rani, and R. C. Amat. An overview of project communication management in construction industry projects, Journal of Management, Economics, and Industrial Organization 1, no. 1, 1-8, 2017.

10. Soliman, Ehab. Communication problems causing governmental projects delay: Kuwait Case Study, International Journal of Construction Project Management 9, no. 1: 1-18, 2017.

11. Abedi, M., M. S. Fathi, and M. F. Mohammad. Effects of construction delays on construction project objectives, The First Iranian Students Scientific Conference in Malaysia, vol. 9, pp. 1-8, 2011.

12. Dainty, Andrew, David Moore, and Michael Murray. Communication in construction: Theory and practice, Routledge, 2007.

13. Berenger, Yembi Renault, and Ngala Agumba Justus. The issue of communication in the construction 
Noman Ahmed et al., International Journal of Emerging Trends in Engineering Research, 9(10), October 2021, 1305 - 1311

industry: a case of South Africa, Proceedings of the Joint International Conference (JIC) on 21st Century Human Habitat: Issues, Sustainability and Development, Akure, Nigeria, pp. 21-24. 2016.

14. Kamalirad, Shirin, Sharareh Kermanshachi, Jennifer Shane, and Stuart Anderson. Assessment of construction projects' impact on internal communication of primary stakeholders in complex projects, Proceedings for the 6th CSCE International Construction Specialty Conference, pp. 074-01. 2017.

15. Sean, Parham, and Yan Li. Study of the effects of communication management on infrastructure projects in Jamaica, 3rd International Symposium on Asian $B \& R$ Conference on International Business Cooperation (ISBCD 2018), pp. 451-459. Atlantis Press, 2018.

16. Wu, Guangdong, Cong Liu, Xianbo Zhao, and Jian Zuo. Investigating the relationship between communication conflict interaction and project success among construction project teams, International Journal of Project Management 35, no. 8, 1466-1482, 2017.

17. Olanrewaju, Abdul Lateef, Seong Yeow Tan, and Lee Foo Kwan, Roles of communication on performance of the construction sector, Procedia engineering 196, pp. 763-770, 2017.

18. Zulch, B. G. Communication: The foundation of project management, Procedia Technology 16, pp. 1000-1009, 2014.

19. Amusan, et al., Adopting information and communication technology in construction industry, International Journal of Mechanical Engineering and Technology (IJMET) 9, no. 1, pp 739-746, 2018.

20. Muszyńska, Karolina, and Susanne Marx, Communication management practices in international projects in Polish and German higher education institutions, Procedia Computer Science 164, pp. 329-336, 2019.

21. Abbas, Ali, Minji Choi, JoonOh Seo, Seung Hyun Cha, and Heng $\mathrm{Li}$, Effectiveness of immersive virtual reality-based communication for construction projects, KSCE Journal of Civil Engineering 23, no. 12, pp. 4972-4983, 2019.

22. Kereri, James Ogechi, and Simon Adamtey, RFID use in residential/commercial construction industry, Journal of Engineering, Design and Technology 2019.

23. Wu, Guangdong, Cong Liu, Xianbo Zhao, and Jian Zuo, Investigating the relationship between communication-conflict interaction and project success among construction project teams. International Journal of Project Management 35, no. 8, pp: 1466-1482, 2017.

24. Schneider, Andrea Kupfer, and Sean McCarthy. Choosing Among Modes of Communication. The Negotiator's Desk Reference (Christopher Honeyman \& Andrea Kupfer Schneider, eds., 2017), Marquette Law School Legal Studies Paper 18-09, 2018.
25. Butt, Aurangzeab, Marja Naaranoja, and Jussi Savolainen. Project change stakeholder communication. International Journal of Project Management 34, no. 8, pp: 1579-1595, 2016.

26. Muszynska, Karolina, K. Dermol, V. Trunk, A. Đakovic, and G. Smrkolj, Communication management in project teams-practices and patterns. In Joint International Conference, pp. 1359-1366, 2015.

27. Kwofie, Titus Ebenezer, Frank Fugar, and Emmanuel Adinyira, Contribution of multiple construction site management features to project team communication effectiveness: The case of mass housing projects. Engineering Project Organization Journal 5, no. 4, pp: 180-193, 2015.

28. Bhalerao, Shilpa, and M. Ingle, Analyzing the modes of communication in agile practices. In 2010 3rd International Conference on Computer Science and Information Technology, vol. 3, pp. 391-395. IEEE, 2010.

29. Leung, Sze-wing, Stephen Mak, and Bill LP Lee, Using a real-time integrated communication system to monitor the progress and quality of construction works, Automation in construction 17, no. 6, pp. 749-757, 2008.

30. Ursachi, George, Ioana Alexandra Horodnic, and Adriana Zait. "How reliable are measurement scales? External factors with indirect influence on reliability estimators, Procedia Economics and Finance 20, pp. 679-686, 2015. 